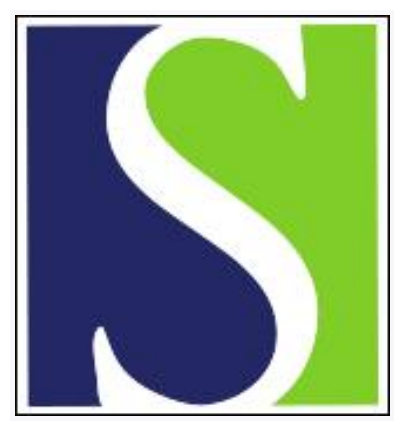

Scand J Work Environ Health 2008;34(1):33-39

https://doi.org/10.5271/sjweh.1189

Issue date: 29 Feb 2008

Relationship between shift work and hypercholesterolemia in Japan

by Dochi M, Sakata K, Oishi M, Tanaka K, Kobayashi E, Suwazono Y

Affiliation: Department of Occupational and Environmental Medicine (A2), Graduate School of Medicine, Chiba University, 1-8-1 Inohana, Chuo-ku, Chiba, 260-8670, Japan. muetani@faculty.chiba-u.jp

Refers to the following texts of the Journal: 2002;28(1):64-71

1997;23(4):257-265 2007;33(1):45-50 2005;31(3):179-183

1998;24(5):351-357 1999;25(3):272-277 1999;25(2):100-104

The following article refers to this text: 2010;36(2):142-149

Key terms: hypercholesterolemia; Japan; longitudinal study; relationship; shift work

This article in PubMed: www.ncbi.nlm.nih.gov/pubmed/18427696 


\title{
Relationship between shift work and hypercholesterolemia in Japan
}

\author{
by Mirei Dochi, MD, ${ }^{1}$ Kouich Sakata, MD, ${ }^{1}$ Mitsuhiro Oishi, MD, ${ }^{1}$ Kumihiko Tanaka, MD, ${ }^{1}$ Etsuko Koba- \\ yashi, PhD, ${ }^{1}$ Yasushi Suwazono, MD ${ }^{1}$
}

\begin{abstract}
Dochi M, Sakata K, Oishi M, Tanaka K, Kobayashi E, Suwazono Y. Relationship between shift work and hypercholesterolemia in Japan. Scand J Work Environ Health. 2008;34(1):33-39.

Objectives The objective of this study was to clarify the influence of shift work on total cholesterol levels in serum in male Japanese workers.

Methods Pooled logistic regression analyses were applied in this 14-year cohort study of 5510 male workers in a steel company. In examining how the adjustments influenced the results, the effect of shift work on the onset of hypercholesterolemia ( $\geq 220 \mathrm{mg} / \mathrm{dl}, 5.7 \mathrm{mmol} / \mathrm{l}$ ) was calculated by adjusting only for age (step 1), for age and lifestyle factors (drinking habit, smoking habit, habitual exercise) (step 2), for age, body mass index (BMI), and the laboratory data [creatinine, glycosylated hemoglobin A1c (HbA1c), aspartic aminotransferase, $\gamma$-glutamyl transpeptidase ( $\gamma$-GTP), uric acid] (step 3), and for age, BMI, lifestyle factors, and the laboratory data (step 4). Results The odds ratio (OR) for shift work with respect to the onset of hypercholesterolemia was significant in step 4 [OR 1.10, 95\% confidence interval (95\% CI) 1.00-1.21, P-value 0.048], whereas the corresponding odds ratios in steps 1, 2, and 3 were not significant. In step 4, the other significant covariates were age (OR 1.01, 95\% CI 1.00-1.02), BMI (OR 1.07, 95\% CI 1.05-1.09), HbA1c (OR 1.07, 95\% CI 1.02-1.11), $\gamma$-GTP (OR 1.03, 95\% CI 1.02-1.04) and alcohol consumption (OR 0.89, 95\% CI 0.81-0.99).

Conclusions In the present study, shift work was shown to be a potential risk factor for hypercholesterolemia among male Japanese workers. However, no consistent association was found between shift work and hypercholesterolemia in the hierarchical evaluation of the statistical model. The present study could not provide wellestablished evidence for a relationship between shift work and hypercholesterolemia.
\end{abstract}

Key terms longitudinal study.

Economic globalization needs continuous processing or operations around the clock to optimize manufacturing systems. Therefore a 24-hour continuous operation system has become popular and has resulted in increasing numbers of workers engaged in shift work in Japan and other industrialized countries. According to the Japanese Ministry of Labor, $22.7 \%$ of Japanese companies had adopted shift work, including night work, in 2005. The proportion of larger companies using shift workers has increased (1).

Several recent studies have indicated that shift work, including night work, is associated with an increased risk of cerebrovascular disease, coronary artery disease, and hypertension (2-10), diabetes mellitus $(11,12)$, other health problems $(13,14)$, and job-related stress (15). Although information so far shows that shift work has adverse health effects to some degree, the pace of economic globalization or the proportion of companies that have adopted shift work has not diminished.
On the other hand, lifestyle-related diseases, which are promoted by factors such as a sedentary lifestyle due to the development of transport, excessive stress, and an increase in the consumption of a high-fat diet, are creating serious problems, mainly in developed nations. Hypercholesterolemia is a lifestyle-related disease that is also thought to be related to the metabolic syndrome and insulin resistance syndrome, which are considered to be risk factors for coronary artery disease (16-18).

On the basis of these backgrounds, the association between shift work and hypercholesterolemia has been investigated. However, most of the previous studies were cross-sectional and did not take confounding factors into account. Among longitudinal studies, the only one considering possible confounding factors was that of Morikawa et al (19), who did not find any significant difference in serum cholesterol levels between shift workers and day workers. Thus the results have been inconsistent, and the information available has not been

1 Department of Occupational and Environmental Medicine, Graduate School of Medicine, Chiba University, Chiba, Japan.

Reprint requests to: Dr M Dochi, Department of Occupational and Environmental Medicine (A2), Graduate School of Medicine, Chiba University, 1-8-1 Inohana, Chuo-ku, Chiba, 260-8670, Japan. [E-mail muetani@ faculty.chiba-u.jp] 
Table 1. Number of participants and the incidence of hypercholesterolemia [total cholesterol $\geq 220 \mathrm{mg} / \mathrm{dl}(5.7 \mathrm{mmol} / \mathrm{l})$ or medication].

\begin{tabular}{|c|c|c|c|c|c|c|}
\hline \multirow[t]{2}{*}{ Age } & \multirow[t]{2}{*}{$\begin{array}{l}\text { Examined } \\
\text { persons (N) }\end{array}$} & \multicolumn{2}{|c|}{$\begin{array}{l}\text { Persons who developed } \\
\text { hypercholesterolemia }\end{array}$} & \multirow[t]{2}{*}{$\begin{array}{l}\text { Person-years of } \\
\text { observation (N) }\end{array}$} & \multirow[t]{2}{*}{$\begin{array}{c}\text { Incidence/ } \\
1000 \text { person-years }\end{array}$} & \multirow[t]{2}{*}{$\begin{array}{c}\text { Observed years/ } \\
\text { person (mean) }\end{array}$} \\
\hline & & $\mathrm{N}$ & $\%$ & & & \\
\hline$\geq 19$ years & 544 & 79 & 14.5 & 3597 & 22.0 & 6.61 \\
\hline $20-29$ years & 1113 & 264 & 23.7 & 6431 & 41.1 & 5.78 \\
\hline 30-39 years & 1677 & 721 & 43.0 & 12602 & 57.2 & 7.51 \\
\hline 40-49 years & 1809 & 796 & 44.0 & 12121 & 65.7 & 6.70 \\
\hline$\geq 50$ years & 367 & 106 & 28.9 & 1276 & 83.1 & 3.48 \\
\hline Total & 5510 & 1966 & 35.7 & 36027 & 54.6 & 6.54 \\
\hline
\end{tabular}

Table 2. Characteristics of the participants in the entry year according to the type of job schedule. $(\mathrm{M}=$ mean)

\begin{tabular}{|c|c|c|c|c|c|c|}
\hline \multirow[t]{2}{*}{ Characteristic } & \multicolumn{3}{|c|}{$\begin{array}{l}\text { Day work } \\
(\mathrm{N}=3263)\end{array}$} & \multicolumn{3}{|c|}{$\begin{array}{l}\text { Shift work } \\
(N=2247)\end{array}$} \\
\hline & M & SD & $\%$ & M & SD & $\%$ \\
\hline Age (years) & 35.1 & 10.82 & . & 36.1 & 9.58 & . \\
\hline $\begin{array}{l}\text { Body mass } \\
\text { index }\left(\mathrm{kg} / \mathrm{m}^{2}\right)\end{array}$ & 23.2 & 2.83 & . & 22.9 & 2.81 & . \\
\hline $\begin{array}{l}\text { Systolic blood } \\
\text { pressure (mmHg) }\end{array}$ & 126.0 & 14.75 & & 125.0 & 14.31 & . \\
\hline $\begin{array}{l}\text { Diastolic blood } \\
\text { pressure (mmHg) }\end{array}$ & 76.9 & 10.81 & . & 77.1 & 10.83 & . \\
\hline Total cholesterol (mg/dl) & 175.9 & 25.00 & . & 175.7 & 24.93 & . \\
\hline Creatinine $(\mathrm{mg} / \mathrm{dl})$ & 0.89 & 0.21 & . & 0.86 & 0.14 & . \\
\hline $\begin{array}{l}\text { Glycosylated } \\
\text { hemoglobin A1c (\%) }\end{array}$ & 4.7 & 0.54 & . & 4.6 & 0.47 & $\cdot$ \\
\hline $\begin{array}{l}\text { Aspartic amino- } \\
\text { transferase }\left(\mathrm{IU} / / / 37^{\circ}\right)\end{array}$ & 21.6 & 19.16 & . & 21.6 & 9.78 & . \\
\hline $\begin{array}{l}\gamma \text {-Glutamyl } \\
\text { transpeptidase (IU/I) }\end{array}$ & 28.8 & 37.11 & . & 29.2 & 35.76 & . \\
\hline Uric acid (mg/dl) & 5.6 & 1.17 & . & 5.5 & 1.20 & . \\
\hline $\begin{array}{l}\text { Alcohol consumption } \\
\text { (everyday) }\end{array}$ & . & . & 36.8 & & & 45.7 \\
\hline Smoking (smoker) & . & . & 58.0 & . & . & 68.8 \\
\hline Habitual exercise (absence) & . & . & 41.6 & . & . & 45.4 \\
\hline
\end{tabular}

sufficient to define the effect of shift work on the onset of hypercholesterolemia.

Therefore, we conducted a longitudinal study to clarify the association between hypercholesterolemia and shift work in a large cohort.

\section{Study population and methods}

\section{Study population}

The design of this study was that of a cohort study from 1991 to 2005 . The participants were 8251 male workers in a Japanese steel company. All of the participants were male because of the absence of female shift workers. All of the workers at this company undergo a legally required health examination once a year. At the same time, a self-administered questionnaire was administered to obtain information about age, past history of disease, present illness, work conditions, and lifestyle. The following persons were excluded from this study: those receiving a health examination for the first time in the final year (2005) of the follow up period $(\mathrm{N}=504)$, those with any missing data in the year of entry $(\mathrm{N}=303)$, those who had been diagnosed with hypercholesterolemia or had initiated therapy for hypercholesterolemia before or in the year of entry $(\mathrm{N}=1432)$, and those for whom the diagnosis of hypercholesterolemia could not be determined in the subsequent year, namely, those for whom the cholesterol measurement or present illness of hypercholesterolemia was missing $(\mathrm{N}=502)$. Finally, 5510 workers comprised this cohort. More than $98 \%$ of the workers in this company underwent an annual health examination every year.

Table 1 gives the number of participants and the incidence of hypercholesterolemia. The total number of persons examined was 5510. The number of persons developing hypercholesterolemia was 1966 (35.7\%). The total number of person-years of observation amounted to 36027 . The mean observed years per person was 6.54 .

Table 2 presents the characteristics of the participants in the entry year according to the type of job schedule. The percentages of those drinking every day, smoking, and without habitual exercise among the shift workers were higher than those of the day workers.

The study protocol was approved by the ethical review board of the Graduate School of Medicine, Chiba University.

\section{Diagnosis}

The detection of the onset of hypercholesterolemia was determined for each person using two types of databases, namely, the results of the annual health examination each year and medical histories through individual interviews. Serum nonfasting blood samples were analyzed enzymatically for total cholesterol in serum. Hypercholesterolemia was classified as either a total serum cholesterol of $\geq 220 \mathrm{mg} / \mathrm{dl}(5.7 \mathrm{mmol} / \mathrm{l})$ or the use of lipid-lowering medication. 
The medical history was investigated through the use a self-administered questionnaire in the annual health examination. In addition, the content was confirmed in individual interviews conducted by occupational health physicians.

\section{Type of job schedule}

The type of job schedule was determined using the payment ledger for March of each year and was divided into shift work and daytime work. The workers engaged in irregular shift work, such as 24-hour work and fixed night work, were excluded. Shift schedule was planned on the basis of four teams, three shifts, and clockwise rotation ( 5 day shifts, 2 rest days; 5 evening shifts, 1 rest day; 5 night shifts, 2 rest days). The day, evening, and night shifts started at 0700, 1500, and 2300, respectively.

\section{Other factors}

Age, body mass index (BMI), blood pressure, level of creatinine (CRE), glycosylated hemoglobin A1c (HbA1c), aspartic aminotransferase (AST), $\gamma$-glutamyl transpeptidase $(\gamma$-GTP), uric acid (UA), alcohol consumption, smoking, and habitual exercise were used as covariates. All of the annual measurements of the other factors during the follow-up period were incorporated into the analysis of the longitudinal observation. Therefore, there were multiple end points (up to 13 points) for each participant. Alcohol consumption was classified into two categories, drinking every day and not drinking every day. Smoking habits were also classified into two categories, smoker and nonsmoker, as was habitual exercise, classified as regular exercise or no regular exercise. Random blood sampling was performed without any restrictions regarding meals. During the first few of the 14 years of the study, the content of the questionnaire changed owing to a change in company policy. Originally, the questionnaire did not ask about the daily frequency of smoking or the quantity of drinking. Consequently, alcohol consumption was characterized simply as "drinking every day" and "not drinking every day", and smoking was characterized simply as "smoking" and "not smoking".

\section{Statistical analysis}

In a multivariate analysis to evaluate the effect of shift work on the onset of hypercholesterolemia in consideration of the confounding factors, a pooled logistic regression model was used. This method was first described by Cupples et al (20). To show how strongly the adjustments influenced the basic association between shift work and hypercholesterolemia, the following hierarchical procedure was carried out. The effect of shift work on the onset of hypercholesterolemia, adjusted for age, was calculated as step 1. Similarly, step 2 was adjusted for age and lifestyle factors. Step 3 was adjusted for age, BMI, and laboratory data, while the final step, step 4, was adjusted for all of the variables. The levels of creatinine, glycosylated hemoglobin A1c, aspartic aminotransferase, $\gamma$-glutamyl transpeptidase, and uric acid were transformed logarithmically in consideration of their distributions. D'Agostino et al (21) have described the pooled logistic regression analysis in detail. We considered a hypothetical study of 1000 persons at risk of a disease. All of these participants had risk factors measured at time $t_{0}$ (or examination 1 ). We followed these participants through the first interval of observation. During that period, 40 participants developed the disease, and 10 others were lost to follow-up. We removed these 50 persons from the population at risk. At time $t_{1}$ (examination 2), there were 950 persons for whom risk factors were measured. Of these, $25 \mathrm{de}-$ veloped the disease, and 5 were lost to follow-up. The remaining 920 persons had risk factors measured at time $t_{2}$ (examination 3), of which 20 developed the disease in the next period, and 10 were lost to follow-up. This method pooled the participants at risk in each interval to yield $2870(1000+950+920)$ person-examinations and pooled the $85(40+25+20)$ disease events. A logistic regression with 2870 observations and 85 events constituted a pooled logistic regression analysis.

Mathematically, the logistic regression model was written as follows (21):

$$
\begin{aligned}
& \operatorname{logit} q_{i}\left(\mathrm{X}\left(t_{i-1}\right)\right)=\log \left(\frac{q_{i}\left(X\left(t_{i-1}\right)\right)}{1-q_{i}\left(X\left(t_{i-1}\right)\right)}\right)= \\
& \alpha+\gamma_{1} \mathrm{X}_{1}\left(\mathrm{t}_{\mathrm{i}-1}\right)+\ldots+\gamma_{p} X_{p}\left(t_{i-1}\right) \gamma,
\end{aligned}
$$

equation 1

where $q_{i}\left(\mathrm{X}\left(t_{i-1}\right)\right)$ is the conditional probability of observing an event by time $t_{i}$ given that the individual is event-free at time $t_{i-1}$, and

$$
\mathrm{X}_{1}\left(\mathrm{t}_{\mathrm{i}-1}\right)=\left(X_{I}\left(t_{i-1}\right), \ldots, X_{p}\left(t_{i-1}\right)\right.
$$

equation 2

is the vector of risk factors measured at time $t_{i-1}$. The parameters obtained were adjusted for the effects of other time-varying (lifestyle and BMI) covariates. Each examination interval of 1 year was treated as a mini-follow-up study. When the person developed hypercholesterolemia during the follow-up, subsequent data were excluded from the analyses. When there were missing data, subsequent data were similarly excluded. The analyses were performed with SPSS 15.0J software (SPSS, Japan Inc, Japan). P-values of $<0.05$ were considered to be statistically significant.

\section{Results}

Table 3 presents the results of the pooled logistic regression analyses according to the adjusted variables. Only 
Table 3. Strength of the adjustments influencing the basic association between shift work and hypercholesterolemia. ( $O R=$ odds ratio, $95 \% \mathrm{Cl}=95 \%$ confidence interval)

\begin{tabular}{|c|c|c|c|}
\hline & $\mathrm{OR}$ & $95 \% \mathrm{Cl}$ & P-value \\
\hline Step $1^{\mathrm{a}}$ & 1.06 & $0.97-1.16$ & 0.207 \\
\hline Step $2^{b}$ & 1.06 & $0.97-1.17$ & 0.197 \\
\hline Step $3^{c}$ & 1.09 & $0.99-1.19$ & 0.074 \\
\hline Step $4^{d}$ & 1.10 & $1.00-1.21$ & 0.048 \\
\hline
\end{tabular}

a Age-adjusted model.

${ }^{\mathrm{b}}$ Model adjusted for age and lifestyle factors (alcohol consumption, smoking, habitual exercise).

c Model adjusted for age, body mass index, and laboratory data (creatinine, glycosylated hemoglobin A1c, aspartic aminotransferase, $\gamma$-glutamyl transpeptidase, uric acid).

${ }^{\mathrm{a}}$ Model adjusted for all of the variables.

Table 4. Independent effects of the variables on predicting the onset of hypercholesterolemia (step 4). (OR = odds ratio, 95\% Cl $=95 \%$ confidence interval)

\begin{tabular}{lccc}
\hline Variable & $\mathrm{OR}^{\mathrm{a}}$ & $95 \% \mathrm{Cl}$ & $\mathrm{P}$-value \\
\hline Job schedule type (shift or day work) & 1.10 & $1.00-1.21$ & 0.048 \\
Age & 1.01 & $1.00-1.02$ & 0.001 \\
Body mass index & 1.07 & $1.05-1.09$ & 0.001 \\
Creatinine & 1.02 & $0.99-1.05$ & 0.137 \\
Glycosylated hemoglobin A1c & 1.07 & $1.02-1.11$ & 0.003 \\
Aspartic aminotransferase & 1.00 & $0.98-1.01$ & 0.959 \\
$\gamma$-Glutamyltranspeptidase & 1.03 & $1.02-1.04$ & 0.001 \\
Uric acid & 0.99 & $0.97-1.01$ & 0.517 \\
Alcohol consumption & & & \\
(everyday or not everyday) & 0.89 & $0.81-0.99$ & 0.027 \\
Smoking (smokers or nonsmokers) & 0.95 & $0.87-1.05$ & 0.341 \\
Habitual exercise (absence or presence) & 1.03 & $0.93-1.13$ & 0.597 \\
\hline
\end{tabular}

a The ratio of the former to the latter was estimated for the type of job schedule, alcohol consumption, smoking, and habitual exercise.

in step 4, in which the model was adjusted for age, BMI, lifestyle factors, and biochemistry data, was the type of job schedule slightly associated with the onset of hypercholesterolemia [odds ratio (OR) 1.10, 95\% confidence interval (95\% CI) 1.00-1.21].

Table 4 presents the results of step 4 in detail. Shift work, age (OR 1.01, 95\% CI 1.00-1.02), BMI (OR 1.07, 95\% CI 1.05-1.09), glycosylated hemoglobin A1c (OR $1.07,95 \%$ CI 1.02-1.11), and $\gamma$-glutamyl transpeptidase (OR $1.03,95 \%$ CI 1.02-1.04) were positively associated with the onset of hypercholesterolemia. On the other hand, alcohol consumption was negatively associated with the onset of hypercholesterolemia (OR 0.89, 95\% CI 0.81-0.99).

\section{Discussion}

There have been several cross-sectional and longitudinal studies on the relationship between shift work and hypercholesterolemia. Of the cross-sectional studies, some concluded that shift work may be a risk factor for the onset of hypercholesterolemia, and others concluded that it was not (22-29). Even studies considering possible confounding factors such as age, anthropometric data, blood pressure, biochemical data, smoking, and alcohol consumption did not provide consistent results regarding the relationship between shift work and hypercholesterolemia. Since a study on the health effects of shift work should take into account the healthy worker effect, cross-sectional studies would not be able to exclude that effect and thus have less reliability than longitudinal studies do. Of the longitudinal studies, some concluded that shift work may be a risk factor for the onset of hypercholesterolemia, and others concluded that it is not $(19,30)$. Among them, the only study considering possible confounding factors was that of Morikawa et al (19), who followed up 1529 male workers for 10 years. Their study population comprised 1529 male blue-collar workers, aged 19-49 years at baseline. The participants were divided into four groups according to their work schedules at baseline, the end point being workers doing fixed daytime work in both years (day-day), workers who changed from shift work to fixed daytime work (shift-day), workers who changed from fixed daytime work to shift work (day-shift), and workers doing shift work in both years (shift-shift). The relationship between changes in serum total cholesterol during the 10 -year period and work schedule and other confounding factors (age, BMI, smoking, alcohol consumption, level of physical activity) were analyzed with a multiple linear regression. In the results, there was no significant difference in the serum cholesterol levels between the shift workers and day workers.

As has already been mentioned, most previous studies on the relationship between shift work and hypercholesterolemia were cross-sectional with simple statistical analyses, and they did not take into account confounding factors. Even in longitudinal studies, the follow-up period was short, the number of participants was small, and confounding factors were not considered except in Morikawa et al's study (19). However, their study compared only two sets of data, at the baseline and after 10 years, and they did not take changes in lifestyle into account.

In our present study, we performed a pooled logistic regression analysis. An advantage of this method is that it allows an evaluation of repeated measurements of work conditions and lifestyle, which may change over time in the multivariate models. The pooled logistic regression analysis is equivalent to a Cox time-dependent regression analysis (21). A strength of this method is that the odds ratios obtained are adjusted for the covariates in the multivariate model and are updated at each annual examination $(31,32)$. This method of analysis has been used frequently in recent years $(6,7,31-37)$. 
Three mechanisms have been implicated in the health effects of shift work (38). First, shift work has various influences on the human body by interfering with the circadian rhythm. The second mechanism works through behavioral changes including dietary habits, smoking, and the absence of habitual exercise. In our present study, the shift workers showed significantly worse habits than the day workers. As for dietary habits, Lennernas et al (39) reported that 22 shift workers who redistributed their eating mostly to the night shift had higher levels of serum total cholesterol. Furthermore, other studies have surmised that an elevated risk of ischemic heart disease due to night work may be related to eating habits $(40,41)$. As a matter of fact, the detailed individual interviews of the shift workers in our study revealed that they usually took meals four times per day during the night shift. For example, on the night shift (from 2300 to 0700 ), the shift workers took meals around 0200, 0900, 1400, and 1800. Although four meals a day might promote obesity in shift workers, BMI was included as a confounding factor in the model in our study, and obesity would not be considered to cause hypercholesterolemia. It may be reasonable to consider that a confusion of meal times and interference with the circadian rhythm may promote the onset of hypercholesterolemia. As for the effect of shift work on body weight, several previous studies have shown a significant effect of shift work on body weight and also the tendency for workers to become overweight (43-48). In contrast, other studies failed to show such associations $(25,27,49)$. As all of these studies were cross-sectional in design, the relationship between shift work and body weight was not determined conclusively.

The third mechanism is social disruption, which makes it difficult for shift workers to stay with their families, to contact their friends who are regular day workers, and to fulfill the various social roles expected by society. This mechanism could be thought to cause stress. In one study, night workers were found to have higher levels of catecholamine, a stress hormone, than day workers (30), and in another study stress increased total serum cholesterol (42).

The results of our study may be explained by a combination of the first and third mechanisms, since alcohol consumption, smoking, and exercise were taken into account as confounding factors. The third factor, stress, is thought to be an essential factor having some influence on all workers. In a future study, it will be necessary to administer a stress questionnaire.

One more result of our study was that alcohol consumption decreased the total serum cholesterol level. Most prospective studies have consistently shown that moderate alcohol intake has a protective effect against coronary heart disease (CHD). The epidemiologic evidence suggests a J-shaped relationship between alcohol and CHD. The plausible mechanisms for the putative cardioprotective effects could include increased levels of high-density lipoprotein cholesterol and decreased levels of low-density lipoprotein cholesterol (50). That is to say that alcohol consumption may improve the lipid profile. The alcohol benefit could depend on the quantity of drinking. In our study, the questionnaire did not ask about the quantity of drinking due to company policy (see the Methods section). Consequently, drinking habits were simply characterized as "drinking every day" and "not drinking every day". Although we did not measure the quantity of alcohol, the cohort was large, and the follow-up period was long. Furthermore, in our study, several variables were included as confounding factors. On the basis of these conditions, the result of our study could be valuable, to some extent, in predicting the association between alcohol and cholesterol.

Although we did not investigate other factors, such as type of work, during all of the follow-up periods, an extensive questionnaire was administered in 2002. On the basis of our results published in 2005 (15), regarding the types of work, the percentage of onsite workers was $90 \%$ for the shift workers and $40 \%$ for the day workers. Of the day workers, $20 \%$ was engaged in office work, and $22 \%$ was in research or technical work. In this company, onsite workers are engaged in activities related to steel production and equipment maintenance. Onsite workers usually monitor and operate the production process remotely in a safe and comfortable operation room, without the demand for heavy physical labor. Occasionally, these workers enter the production site to carry out equipment maintenance while the production process is suspended. Therefore, type of work was not a major confounding factor in our study. Thus the type of work was not the major confounding factor. On the other hand, socioeconomic status such as income level, marital status, and educational level may have influenced our results. The economic status of the shift workers was generally good due to their receiving shift differential pay provided by a large Japanese steel company. Marital status and living arrangement did not differ between the day and shift workers. Namely, $78.7 \%$ of the day workers were married (shift workers $73.4 \%$ ), and $86.1 \%$ of the day workers were living with their families (shift workers $85.6 \%$ ). As for the educational levels, the proportion of those educated to the high school level or less was actually around $70 \%$ for the day workers and around 90\% for the shift workers. Previous studies in Europe and the United States have shown that people with higher educational levels have better health practices. However, several epidemiologic studies have suggested that the relationship between health status and educational level is weaker in Japan than in Europe or in the United States. Anzai et al (51) reported that higher education was associated with shorter sleeping hours for both 
men and women, and a lower BMI for women. In the age groups younger than 70 years, people with a higher education tended to exercise more. Smoking for women, alcohol consumption, and a health practices index were not related to educational level. Martikainen et al (52) reported that those with a higher educational level had a higher BMI and waist-to-hip-ratio and a lower highdensity lipoprotein cholesterol level in Japan, and this picture differed from that of an English cohort. Nishi et al (53) reported that there was no relationship between educational level and hypertension or hypercholesterolemia and that diabetes was inversely associated with educational level among Japanese men. In these studies, smoking was inversely associated with educational level. However, we included major lifestyle factors, which differed between educational levels in previous reports in Japan, into the statistical model in our study. Therefore, the effect of educational level was sufficiently adjusted for. Thus we believe that the results of our study were not biased due to socioeconomic status.

Within research on shift workers, the healthy worker effect is usually taken into consideration; in other words, shift workers who have any health problems are moved to day work. However, at the company surveyed in our study, most of the transfers from shift work to regular day work were done for work-related reasons, and transfers due to health problems amounted to no more than a few a year. Consequently, the healthy worker effect was regarded as not having influenced these results.

In our study, shift work was shown to be a potential risk factor for increased total serum cholesterol among male Japanese workers. However, we did not find a consistent association between shift work and hypercholesterolemia in our hierarchical evaluation of the statistical model. Therefore, we are of the opinion that our study did not provide well-established evidence for a relationship between shift work and hypercholesterolemia.

\section{Acknowledgments}

This study was supported by grants from the Japan Society for the Promotion of Science (Grant-in-Aid for Scientific Research, (C)(2) no 14570323, and Grantin-Aid for Scientific Research, (C) no. 17590508), and from the Occupational Health Promotion Foundation (2000, 2002).

\section{References}

1. Ministry of Health, Labor and Welfare. General survey on working conditions in 2005 [In Japanese]. Tokyo: Ministry of Health, Labor and Welfare; 2005.
2. Knutsson A, Akerstedt T, Jonsson BG, Orth-Gomer K. Increased risk of ischaemic heart disease in shift workers. Lancet. 1986;2:89-92.

3. Knutsson A, Hallquist J, Reuterwall C, Theorell T, Akerstedt T. Shiftwork and myocardial infarction: a case-control study. Occup Environ Med. 1999;56:46-50.

4. Morikawa Y, Nakagawa H, Miura K, Ishizaki M, Tabata M, Nishijo M, et al. Relationship between shift work and onset of hypertension in a cohort of manual workers. Scand J Work Environ Health. 1999;25(2):100-4.

5. Murata K, Yano E, Shinozaki T. Impact of shift work on cardiovascular functions in a 10-year follow-up study. Scand J Work Environ Health. 1999;25(3):272-7.

6. Oishi M, Suwazono Y, Sakata K, Okubo Y, Harada H, Kobayashi E, et al. A longitudinal study on the relationship between shift work and the progression of hypertension in male Japanese workers. J Hypertens. 2005;23:2173-8.

7. Sakata K, Suwazono Y, Harada H, Okubo Y, Kobayashi E, Nogawa K. The relationship between shift work and the onset of hypertension in male Japanese workers. J Occup Environ Med. 2003;45:1002-6.

8. Tenkanen L, Sjöblom T, Härmä M. Joint effect of shift work and adverse life-style factors on the risk of coronary heart disease. Scand J Work Environ Health. 1998;24(5):351-7.

9. Åkerstedt T, Knutsson A, Alfredsson L, Theorell T. Shift work and cardiovascular disease. Scand J Work Environ Health. 1984;10:409-14.

10. Alfredsson L, Karasek R, Theorell T. Myocardial infarction risk and psychosocial work environment: an analysis of the male Swedish working force. Soc Sci Med. 1982;16:463-7.

11. Morikawa Y, Nakagawa H, Miura K, Soyama Y, Ishizaki M, Kido T, et al. Shift work and the risk of diabetes mellitus among Japanese male factory workers. Scand J Work Environ Health. 2005;31(3):179-83.

12. Suwazono Y, Sakata K, Okubo Y, Harada H, Oishi M, Kobayashi E, et al. Long-term longitudinal study on the relationship between alternating shift work and the onset of diabetes mellitus in male Japanese workers. J Occup Environ Med. 2006;48:455-61.

13. Uetani M, Suwazono Y, Kobayashi E, Inaba T, Oishi M, Nogawa K. A longitudinal study of the influence of shift work on serum uric acid levels in workers at a telecommunications company. Occup Med (Lond). 2006;56:83-8.

14. Segawa K, Nakazawa S, Tsukamoto Y, Kurita Y, Goto H, Fukui A, et al. Peptic ulcer is prevalent among shift workers. Dig Dis Sci. 1987;32:449-53.

15. Harada H, Suwazono Y, Sakata K, Okubo Y, Oishi M, Uetani $\mathrm{M}$, et al. Three-shift system increases job-related stress in Japanese workers. J Occup Health. 2005;47:397-404.

16. Gotto AM, Gorry GA, Thompson JR, Cole JS, Trost R, Yeshurun D, et al. Relationship between plasma lipid concentrations and coronary artery disease in 496 patients. Circulation. 1977;56:875-83.

17. Kagan A, Harris BR, Winkelstein W Jr, Johnson KG, Kato $\mathrm{H}$, Syme SL, et al. Epidemiologic studies of coronary heart disease and stroke in Japanese men living in Japan, Hawaii and California: demographic, physical, dietary and biochemical characteristics. J Chronic Dis. 1974;27:345-64.

18. Kannel WB, Dawber TR, Kagan A, Revotskie N, Stokes J III. Factors of risk in the development of coronary heart disease-six year follow-up experience: the Framingham Study. Ann Intern Med. 1961;55:33-50.

19. Morikawa Y, Nakagawa H, Miura K, Soyama Y, Ishizaki M, Kido T, et al. Effect of shift work on body mass index 
and metabolic parameters. Scand J Work Environ Health 2007;33(1):45-50.

20. Cupples LA, D'Agostino RB, Anderson K, Kannel WB. Comparison of baseline and repeated measure covariate techniques in the Framingham Heart Study. Stat Med. 1988;7:205-22.

21. D'Agostino RB, Lee ML, Belanger AJ, Cupples LA, Anderson K, Kannel WB. Relation of pooled logistic regression to time dependent Cox regression analysis: the Framingham Heart Study. Stat Med. 1990;9:1501-15.

22. Nakamura K, Shimai S, Kikuchi S, Tominaga K, Takahashi $\mathrm{H}$, Tanaka M, et al. Shift work and risk factors for coronary heart disease in Japanese blue-collar workers: serum lipids and anthropometric characteristics. Occup Med (Lond). 1997;47:142-6.

23. Knutson A, Andersson H, Berglund U. Serum lipoproteins in day and shift workers: a prospective study. Br J Ind Med. 1990;47:132-4.

24. Ha M, Park J. Shiftwork and metabolic risk factors of cardiovascular disease. J Occup Health. 2005;47:89-95.

25. Ghiasvand M, Heshmat R, Golpira R, Haghpanah V, Soleimani A, Shoushtarizadeh P, et al. Shift working and risk of lipid disorders: a cross-sectional study. Lipids Health Dis. 2006;5:9.

26. Bursey RG. A cardiovascular study of shift workers with respect to coronary artery disease risk factor prevalence. J Soc Occup Med. 1990;40:65-7.

27. Knutsson A, Åkerstedt T, Jonsson BG. Prevalence of risk factors for coronary artery disease among day and shift workers. Scand J Work Environ Health. 1988;14:317-21.

28. Romon M, Nuttens MC, Fievet C, Pot P, Bard JM, Furon D, et al. Increased triglyceride levels in shift workers. Am J Med. 1992;93:259-62.

29. Tenkanen L, Sjöblom T, Kalimo R, Alikoski T, Härmä M. Shift work, occupation and coronary heart disease over 6 years of follow-up in the Helsinki Heart Study. Scand J Work Environ Health. 1997;23(4):257-65.

30. Theorell T, Akerstedt T. Day and night work: changes in cholesterol, uric acid, glucose and potassium in serum and in circadian patterns of urinary catecholamine excretion: a longitudinal cross-over study of railway workers. Acta Med Scand. 1976;200:47-53.

31. Benjamin EJ, Wolf PA, D'Agostino RB, Silbershatz H, Kannel WB, Levy D. Impact of atrial fibrillation on the risk of death: the Framingham Heart Study. Circulation. 1998;98:946-52.

32. Fairfield KM, Willett WC, Rosner BA, Manson JE, Speizer FE, Hankinson SE. Obesity, weight gain, and ovarian cancer. Obstet Gynecol. 2002;100:288-96.

33. Solomon DH, Karlson EW, Rimm EB, Cannuscio CC, Mandl LA, Manson JE, et al. Cardiovascular morbidity and mortality in women diagnosed with rheumatoid arthritis. Circulation. 2003;107:1303-7.

34. Schett G, Kiechl S, Redlich K, Oberhollenzer F, Weger S, Egger $\mathrm{G}$, et al. Soluble RANKL and risk of nontraumatic fracture. JAMA. 2004;291:1108-13.

35. Higashikawa A, Suwazono Y, Okubo Y, Uetani M, Kobayashi E, Kido T, et al. Association of working conditions and lifestyle with increased serum gamma-glutamyltransferase: a follow-up study. Arch Med Res. 2005;36:567-73.

36. Suwazono Y, Kobayashi E, Uetani M, Miura K, Morikawa Y, Ishizaki M, et al. The -1438A/G polymorphism in the 5-hydroxytryptamine receptor $2 \mathrm{~A}$ gene is related to hyperuricemia, increased gamma-glutamyl transpeptidase and decreased highdensity lipoprotein cholesterol level in the Japanese population: a prospective cohort study over 5 years. Int J Mol Med.
2006;17:77-82.

37. Suwazono Y, Okubo Y, Kobayashi E, Kido T, Nogawa K. A follow-up study on the association of working conditions and lifestyles with the development of (perceived) mental symptoms in workers of a telecommunication enterprise. Occup Med (Lond). 2003;53:436-42.

38. Knutsson A, Boggild H. Shiftwork and cardiovascular disease: review of disease mechanisms. Rev Environ Health. 2000;15:359-72.

39. Lennernäs M, Åkerstedt T, Hambræus L. Nocturnal eating and serum cholesterol of three-shift workers. Scand J Work Environ Health. 1994;20:401-6.

40. Armstrong S. A chronometric approach to the study of feeding behavior. Neurosci Biobehav Rev. 1980;4:27-53.

41. Halberg F. Some aspects of the chronobiology of nutrition: more work is needed on "when to eat". J Nutr. 1989;119:33343.

42. Clark DA, Arnold EL, Foulds EL Jr, Brown DM, Eastmead DR, Parry EM. Serum urate and cholesterol levels in Air Force Academy cadets. Aviat Space Environ Med. 1975;46:1044-8.

43. Boggild H, Suadicani P, Hein HO, Gyntelberg F. Shift work, social class, and ischaemic heart disease in middle aged and elderly men; a 22 year follow up in the Copenhagen Male Study. Occup Environ Med. 1999;56:640-5.

44. Di Lorenzo L, De Pergola G, Zocchetti C, L'Abbate N, Basso A, Pannacciulli N, et al. Effect of shift work on body mass index: results of a study performed in 319 glucose-tolerant men working in a Southern Italian industry. Int J Obes Relat Metab Disord. 2003;27:1353-8.

45. Ishizaki M, Morikawa Y, Nakagawa H, Honda R, Kawakami $\mathrm{N}$, Haratani T, et al. The influence of work characteristics on body mass index and waist to hip ratio in Japanese employees. Ind Health. 2004;42:41-9.

46. Karlsson B, Knutsson A, Lindahl B. Is there an association between shift work and having a metabolic syndrome?: results from a population based study of 27,485 people. Occup Environ Med. 2001;58:747-52.

47. Parkes KR. Shift work and age as interactive predictors of body mass index among offshore workers. Scand J Work Environ Health. 2002;28(1):64-71.

48. van Amelsvoort LG, Schouten EG, Kok FJ. Duration of shiftwork related to body mass index and waist to hip ratio. Int $\mathrm{J}$ Obes Relat Metab Disord. 1999;23:973-8.

49. Karlsson BH, Knutsson AK, Lindahl BO, Alfredsson LS. Metabolic disturbances in male workers with rotating three-shift work. Results of the WOLF study. Int Arch Occup Environ Health. 2003;76:424-30.

50. Agarwal DP. Cardioprotective effects of light-moderate consumption of alcohol: a review of putative mechanisms. Alcohol Alcohol. 2002;37:409-15.

51. Anzai Y, Ohkubo T, Nishino Y, Tsuji I, Hisamichi S. Relationship between health practices and education level in the rural Japanese population. J Epidemiol. 2000;10:149-56.

52. Martikainen P, Ishizaki M, Marmot MG, Nakagawa H, Kagamimori S. Socioeconomic differences in behavioural and biological risk factors: a comparison of a Japanese and an English cohort of employed men. Int J Epidemiol. 2001;30:833-8.

53. Nishi N, Makino K, Fukuda H, Tatara K. Effects of socioeconomic indicators on coronary risk factors, self-rated health and psychological well-being among urban Japanese civil servants. Soc Sci Med. 2004;58:1159-70.

Received for publication: 11 April 2007 